\title{
Prevalence and characteristics of alcohol consumption and risk of type 2 diabetes mellitus in rural China
}

Xueyan $\mathrm{Wu}^{1 \dagger}$, Xiaotian Liu' ${ }^{1 \dagger}$, Wei Liao' ${ }^{1}$ Ning Kang ${ }^{1}$, Xiaokang Dong ${ }^{1}$, Tanko Abdulai ${ }^{1}$, Zhihan Zhai ${ }^{1,2}$, Chongjian Wang ${ }^{1}$, Xiaoqiong Wang ${ }^{3^{*}}$ and Yuqian $\mathrm{Li}^{4^{*}}$

\begin{abstract}
Background: The study aimed to characterize the prevalence of alcohol consumption and further investigate the relationship between alcohol consumption and type 2 diabetes mellitus (T2DM).

Methods: We studied 39,259 participants aged 18 to 79 years of the Henan Rural Cohort study. The associations between alcohol consumption and T2DM were examined using the logistic regression models and restricted cubic spline.

Results: For men, alcohol abstinence was associated with an increased risk of T2DM $(1.491(1.265,1.758))$, whereas current drinkers were not associated with $\operatorname{T2DM}(1.03(0.91,1.15))$. Further analysis of alcohol drinkers revealed that only high-risk drinkers of WHO drinking risk levels increased the risk of T2DM $(1.289(1.061,1.566))$ compared to never drinkers. The risk of T2DM increased as the age of starting to consume alcohol decreased and as the number of years of consuming alcohol and the alcohol intake increased only in men. We further found that the risk of T2DM decreased as the number of years of abstinence increases and no association between alcohol abstinence and T2DM was found after more than 10 years of abstinence among men.

Conclusions: Our results suggested that reducing the amount of alcohol consumed and adhering to abstinence from alcohol consumption are beneficial in reducing the risk of T2DM.

Trial registration: The Henan Rural Cohort Study has been registered at Chinese Clinical Trial Register (Registration number: ChiCTR-OOC-15006699). Date of registration: 2015-07-06. http://www.chictr.org.cn/showproj.aspx?proj=113 75
\end{abstract}

Keywords: Alcohol, Abstinence, WHO drinking risk levels, Type 2 diabetes mellitus, Rural population

\footnotetext{
*Correspondence: xwzty@126.com; liyuqian@zzu.edu.cn

${ }^{+}$Xueyan Wu and Xiaotian Liu contributed equally to this work.

${ }^{3}$ Department of Economics, School of Business, Zhengzhou University,

Zhengzhou, Henan, P. R. China

${ }^{4}$ Department of Clinical Pharmacology, School of Pharmaceutical Science,

Zhengzhou University, Zhengzhou, Henan, P. R. China

Full list of author information is available at the end of the article
}

(c) The Author(s). 2021 Open Access This article is licensed under a Creative Commons Attribution 4.0 International License, which permits use, sharing, adaptation, distribution and reproduction in any medium or format, as long as you give appropriate credit to the original author(s) and the source, provide a link to the Creative Commons licence, and indicate if changes were made. The images or other third party material in this article are included in the article's Creative Commons licence, unless indicated otherwise in a credit line to the material. If material is not included in the article's Creative Commons licence and your intended use is not permitted by statutory regulation or exceeds the permitted use, you will need to obtain permission directly from the copyright holder. To view a copy of this licence, visit http://creativecommons.org/licenses/by/4.0/ The Creative Commons Public Domain Dedication waiver (http://creativecommons.org/publicdomain/zero/1.0/) applies to the data made available in this article, unless otherwise stated in a credit line to the data. 


\section{Background}

Alcohol consumption and health have a complex connection. Alcohol consumption is one of the leading risk factors for death and disease worldwide, and studies link its consumption to 60 acute and chronic diseases [1-4]. Since 2000, the percentage of people who drink alcohol globally has fallen from 47.6 to $43.0 \%$, a decline of nearly 5\% [4]. Nevertheless, the percentage of current drinkers is rising, in the Western Pacific region dominated by China [5]. Per capita alcohol consumption in China rose from 4.11 in 2005 to 7.11 in 2010, which was higher than the world average [4]. Compared to other countries, China has a different demographic profile and a specific "drinking culture". Alcohol consumption is very common during important festivals, business occasions, ceremonies, and special events in China. The Survey on the Health and Nutrition Status of the Chinese Population showed that the alcohol consumption rate in China in the past year was about 34\% [6]. Moreover, alcohol consumption is a normal part of the daily diet, especially in rural areas of China.

China has a large burden of diabetes in recent years [7]. Diabetes is a major public health issue in China, especially type 2 diabetes mellitus (T2DM). China has a large health burden of diabetes: in 2013, a quarter of diabetic patients worldwide were in China, where $11.6 \%$ of adults had diabetes and $50.1 \%$ had prediabetes [8]. Alcohol consumption was one of the risk factors of T2DM. However, the existing literature on the relationship between alcohol consumption and T2DM is inconsistent and controversial. The majority of the studies revealed that moderate alcohol consumption with a decrease in the risk of diabetes, whereas high alcohol intake was associated with a higher risk [9-15]. There are still a few studies that show that alcohol consumption increases the incidence of T2DM, regardless of the amount of alcohol consumed [16-18]. Nevertheless, the definitions of moderate and high alcohol intake have varied across studies. World Health Organization (WHO) risk drinking levels is associated with health beneficial effects [19, 20]. In a US national survey with follow-up studies, a reduction in WHO high-risk drinking levels was found to be associated with a reduced risk of cardiovascular disease among very-high-risk and high-risk drinkers, further demonstrating that reducing high levels of alcohol consumption has important benefits in multiple clinical areas [21]. However, no studies have been found on the relationship between WHO risk drinking levels of alcohol consumption and diabetes.

In addition, few studies have been conducted on resource-constrained areas. As a result, we conducted a large population-based study to characterize the prevalence of alcohol consumption and to further investigate the relationship between different lengths of abstinence and different WHO drinking risk levels of alcohol consumption and T2DM in rural areas of China.

\section{Methods \\ Study design and participants}

This study population is from the Henan Rural Cohort Study. From July 2015 to September 2017, the cohort was conducted in Yuzhou county, Suiping county, Xinxiang county, Kaifeng county, and Yima county of Henan Province in China. A multi-stage, stratified cluster sampling method was used to select the sample. Rural areas with signed informed consent forms were selected as the study sample. The details of this cohort have been introduced elsewhere [22]. Finally, 39,259 subjects were included in this study. Written informed consent was obtained from each participant prior to data collection.

The Henan Rural Cohort Study was approved by the Zhengzhou University Life Science Ethics Committee (Code: [2015] MEC (S128)), and was conducted according to the 1975 Declaration of Helsinki.

\section{Data collection}

Detailed information about sociodemographic characteristics (age, gender, education level, marital status, and per capita monthly income), lifestyle factors (smoking, alcohol consumption, and physical activity), and personal history of chronic diseases was collected through face-to-face interviews with standardized questionnaires [23]. The physical activity was assessed using International Physical Activity Questionnaire (IPAQ 2001) [24]. Data on diet intake via a validated Food Frequency Questionnaire (FFQ) [25]. The FFQ based on the Dietary Guidelines for Chinese Residents and the eating habits.

The height and weight of participants were measured twice, and the average readings were computed to analyze. Body mass index $\left(\mathrm{BMI}, \mathrm{kg} / \mathrm{m}^{2}\right)$ was calculated as weight $(\mathrm{kg})$ divided the square of height $(\mathrm{m})$. Blood pressure was measured three times by electronic sphygmomanometer in the right arm in a sitting position after at least $5 \mathrm{~min}$ rest. There were 30 s intervals between the three measurements. Venous blood samples were collected from subjects after an overnight fast of at least $8 \mathrm{~h}$ and stored in $-80{ }^{\circ} \mathrm{C}$ cryogenic refrigerator before analysis. The fasting blood glucose (FBG) was analyzed via glucose oxidative method (GOD-PAP) by ROCHE Cobas C501 automatic biochemical analyzer. Total cholesterol was measured by Roche Cobas C501 automatic biochemical analyzer. The details of the equipment for anthropometric and clinical examinations have been introduced elsewhere [22]. T2DM Patients were defined as those who had an FPG $\geq 7.0 \mathrm{mmol} / \mathrm{L}$, or diagnosed T2DM by physicians and using anti-glycemic drugs in the last 2 weeks [26]. 


\section{Alcohol consumption estimation}

Alcohol consumption was collected through a face-toface interview questionnaire, which included screening questions to distinguish current drinkers, former drinkers, and lifetime abstainers, and parallel question groups on the types of drinking (beer, liquor, red wine, and rice wine). Participants were asked whether they had ever consumed alcoholic drinks, and if they had, they were asked whether they were former-drinkers or current-drinkers. For current-drinkers, they were additionally asked to fill out a questionnaire asking about the amount and frequency of alcohol consumption. Participants were asked about the frequency (daily, weekly, monthly, yearly, or never) and amount of their consumption of every kind of wine in the past 12 months. Total daily alcohol consumption was calculated using the average frequency, amount per occasion, and alcohol content. Consistent with the Chinese Dietary Guidelines summary [27], we calculated WHO drinking risk levels [28] based on participant's reports of the number of standard drinks consumed, which were transformed into grams of pure alcohol. The 4 risk levels are defined as following: high-risk drinkers $(>60 \mathrm{~g} / \mathrm{d}$ for men, $>40 \mathrm{~g} / \mathrm{d}$ for women); medium-risk drinkers ( $>25$ to $60 \mathrm{~g} / \mathrm{d}$ for men, $>15$ to $40 \mathrm{~g} / \mathrm{d}$ for women), low-risk ( $>0$ to $25 \mathrm{~g} / \mathrm{d}$ for men,>0 to $15 \mathrm{~g} / \mathrm{d}$ for women), and non-drinkers [28].

\section{Statistical analysis}

Continuous variables were expressed as mean and standard deviation, whereas categorical variables were expressed as percentages. All analyses were performed using the student t-test, Pearson's correlation coefficient, or one-way analysis of variance test. To further visually observe association between the changes of age of starting to consume alcohol and alcohol intake and T2DM, multivariable restricted cubic regression splines with three knots placed at the fifth, 50th and 95th was performed by SAS version 9.1 (RCS_Reg v1.0.sas) and R version 3.6.3 (ggplot2). The multivariable logistic regression model was conducted to investigate the relationship between drinking status, duration of abstinence, WHO drinking risk levels and risk of T2DM, and three models were established: Model 1 was unadjusted; Model 2 was adjusted for age, marital status, average monthly individual income, education level, smoking, more vegetables and fruits intake, high fat diet for the variables in the Model 1 plus dyslipidemia, hypertension, and family histories of hypertension and T2DM; Model 3 was adjusted for the variables in the Model 2 plus more vegetables and fruits intake, high- fat diet, physical activity, and family histories of T2DM. $P$ values $<0.05$ were considered statistically significant. All statistical analyses were performed using SPSS software V.26.0, SAS version 9.1 (RCS_Reg v1.0.sas), and R version 3.6.3.

\section{Results \\ Characteristics of the studied population}

Of all 39,259 participants, 23,769 (60.54\%) were women and the mean age was $55.60 \pm 12.19$ years. 3708 (1411 in men and 2297) cases of T2DM were identified. The prevalence of never drinkers, former drinkers, and current drinkers was $77.30 \%$ (46.85\% in men and $97.14 \%$ in women), $4.67 \%$ (11.41\% in men and $0.27 \%$ in women), and $18.03 \%$ ( $41.74 \%$ in men and $2.59 \%$ in women), respectively. Lower age, higher education levels, income, SBP and DBP, higher proportion of current smokers and obesity were observed among those who were current drinkers compared to non-current drinkers. Similar results were observed in men, while higher proportion of overweight, lower TC and FPG were observed among women who were current drinkers compared to noncurrent drinkers (Table 1 and Table S1). The WHO risk drinking levels of high-risk drinkers, medium-risk drinkers and low-risk drinkers were $3.90 \%(9.63 \%$ in men and $0.17 \%$ in women), $4.71 \%$ (11.38\% in men and $0.36 \%$ in women) and $13.87 \%$ (31.69\% in men and $2.26 \%$ in women), respectively (Table S2). A summary of participants' age of starting to drink, duration of drinking and alcohol intake by sex is show in Table S3. The mean alcohol intake was $19.94 \mathrm{~g} / \mathrm{d}$ in men $(0.29 \mathrm{~g} / \mathrm{d}$ in women, ranging from $>0$ to $246.57 \mathrm{~g} / \mathrm{d}$ ), ranging from $>0$ to $532.60 \mathrm{~g} / \mathrm{d}$. The mean age of starting to drink was 22.45 years in men and 33.37 years in women. The mean duration of drinking was 31.61 years in men and 23.37 years in women. Figure 1 displays the sex-specific distributions of alcohol consumption according to age. There were statistically significant U-shaped associations between the mean levels of alcohol consumption and age groups in men, with the highest mean values among participants with the age of 40 to 49 . Women's alcohol intake was very low and did not change much with age. Fig. S1 and Table S4 show the distribution of age of starting to drink and initiation of sobriety. The percentage of people who started drinking alcohol before the age of 18 reached $25.96 \%$ (26.99\% in men and $11.41 \%$ in women) and the lowest age of starting to drink was 7 . The most prevalent of age group was 18 to 29 both in men $(58.46 \%)$ and women $(33.16 \%)$. The proportion of women who start drinking after the age of 30 was higher than that of men. In addition, most men begin to stop drinking at age 50 to 59 , while most women begin abstaining at age 40 to 49 . Further exploring the reasons for quitting (Fig. S2), we found that most people quit drinking for health reasons such as disease. Furthermore, alcoholic beverages mainly consisted of liquor and beer. 
Table 1 Characteristics of the participants by drinking status

\begin{tabular}{|c|c|c|c|c|c|}
\hline \multirow[t]{2}{*}{ Characteristic, n (\%) } & \multirow{2}{*}{$\begin{array}{l}\text { Total } \\
(n=39,259)\end{array}$} & \multicolumn{3}{|l|}{ Drinking status } & \multirow[t]{2}{*}{$P$} \\
\hline & & Never drinker & Former drinker & Current drinker & \\
\hline Total & $39,259(100.00)$ & $30,347(77.30)$ & $1832(4.67)$ & $7080(18.03)$ & $<0.001$ \\
\hline Age (years, mean $\pm S D$ ) & $55.60 \pm 12.19$ & $55.89 \pm 12.17$ & $60.61 \pm 10.10$ & $53.05 \pm 12.20$ & $<0.001$ \\
\hline Sex & & & & & $<0.001$ \\
\hline Men & $15,490(39.46)$ & $7257(46.85)$ & $1768(11.41)$ & $6465(41.74)$ & \\
\hline Women & $23,769(60.54)$ & $23,090(97.14)$ & $64(0.27)$ & $615(2.59)$ & \\
\hline Marital status & & & & & $<0.001$ \\
\hline Married/cohabiting & $35,243(89.77)$ & $27,036(76.71)$ & $1656(4.70)$ & $6551(18.59)$ & \\
\hline Unmarried/divorced/widowed & $4016(10.23)$ & $3311(82.45)$ & $176(4.38)$ & $529(13.17)$ & \\
\hline Education levels & & & & & $<0.001$ \\
\hline Primary school or illiteracy & $17,572(44.76)$ & $14,848(84.50)$ & $707(4.02)$ & $2017(11.48)$ & \\
\hline Junior high school & $15,643(39.85)$ & $11,415(72.97)$ & $807(5.16)$ & $3421(21.87)$ & \\
\hline High school or above & $6044(15.40)$ & $4084(67.57)$ & $318(5.26)$ & $1642(27.17)$ & \\
\hline Income (RMB per month) & & & & & $<0.001$ \\
\hline$<500$ & $14,014(35.70)$ & $11,136(79.36)$ & $753(5.37)$ & $2125(15.16)$ & \\
\hline $500 \sim$ & $12,907(32.88)$ & $10,023(77.66)$ & $576(4.46)$ & $2308(17.88)$ & \\
\hline $1000 \sim$ & $12,338(31.43)$ & $9188(74.47)$ & $503(4.08)$ & $2647(21.45)$ & \\
\hline Smoking & & & & & $<0.001$ \\
\hline Never & $28,580(72.80)$ & 26,235 (91.79) & $273(0.96)$ & $2072(7.25)$ & \\
\hline Former & $3192(8.13)$ & $1184(37.09)$ & $827(25.91)$ & $1180(37.00)$ & \\
\hline Current & $7487(19.07)$ & $2928(39.11)$ & $732(9.78)$ & $3827(51.12)$ & \\
\hline Physical activity & & & & & $<0.001$ \\
\hline Low & $12,715(32.39)$ & $9646(75.86)$ & $754(5.93)$ & $2315(18.21)$ & \\
\hline Moderate & $14,805(37.71)$ & $12,315(83.18)$ & $513(3.47)$ & $1977(13.35)$ & \\
\hline High & $11,739(29.90)$ & $8386(71.44)$ & $565(4.81)$ & $2788(23.75)$ & \\
\hline BMI & & & & & $<0.001$ \\
\hline Underweight & $952(2.43)$ & 787 (82.67) & $51(5.36)$ & $114(11.97)$ & \\
\hline Normal & $15,749(40.25)$ & $12,209(77.52)$ & $808(4.54)$ & $2732(18.58)$ & \\
\hline Overweight & $15,479(39.56)$ & $11,901(76.88)$ & $702(38.57)$ & $2876(40.73)$ & \\
\hline Obesity & $6951(17.76)$ & $5353(77.01)$ & $259(3.73)$ & $1339(19.26)$ & \\
\hline $\mathrm{SBP}(\mathrm{mmHg}$, mean $\pm \mathrm{SD})$ & $125.96 \pm 19.99$ & $125.74 \pm 20.41$ & $127.51 \pm 19.44$ & $126.49 \pm 18.20$ & $<0.001$ \\
\hline $\mathrm{DBP}(\mathrm{mmHg}$, mean $\pm \mathrm{SD})$ & $77.70 \pm 11.64$ & $77.10 \pm 11.44$ & $78.07 \pm 11.86$ & $80.14 \pm 12.12$ & $<0.001$ \\
\hline $\mathrm{TC}(\mathrm{mmol} / \mathrm{L}$, mean $\pm \mathrm{SD})$ & $4.76 \pm 0.99$ & $4.78 \pm 0.99$ & $4.57 \pm 0.97$ & $4.70 \pm 0.97$ & $<0.001$ \\
\hline $\mathrm{FPG}(\mathrm{mmol} / \mathrm{L}$, mean $\pm \mathrm{SD})$ & $5.54 \pm 1.51$ & $5.54 \pm 1.51$ & $5.64 \pm 1.63$ & $5.52 \pm 1.47$ & 0.013 \\
\hline T2DM (yes) & $3708(1000))$ & $2924(78.86)$ & $239(6.45)$ & $545(14.70)$ & $<0.001$ \\
\hline
\end{tabular}

Abbreviations: SD standard deviation, RMB Renminbi, BMI body mass index, SBP systolic blood pressure, DBP diastolic blood pressure, TC total cholesterol, FPG fasting plasma glucose, $T 2 D M$ type 2 diabetes mellitus

Beer intake decreased with age, while liquor consumption increased (Fig. S3).

\section{Associations between alcohol consumption and T2DM}

The association between alcohol consumption and T2DM according sex is shown in Table 2. For men, after adjusting for the potential confounding factors, compared to non-drinkers, alcohol abstinence was associated with an increased risk of T2DM $(1.49(1.27,1.76))$, while current drinkers were not associated with T2DM $(1.00(0.88,1.13))$. Further analysis of alcohol drinkers revealed that only high-risk drinkers increased the risk of T2DM $(1.289(1.061,1.566))$ compared to never drinkers. In women, no association was found between alcohol abstinence and T2DM. however, alcohol consumption might reduce the risk of T2DM compared with never 


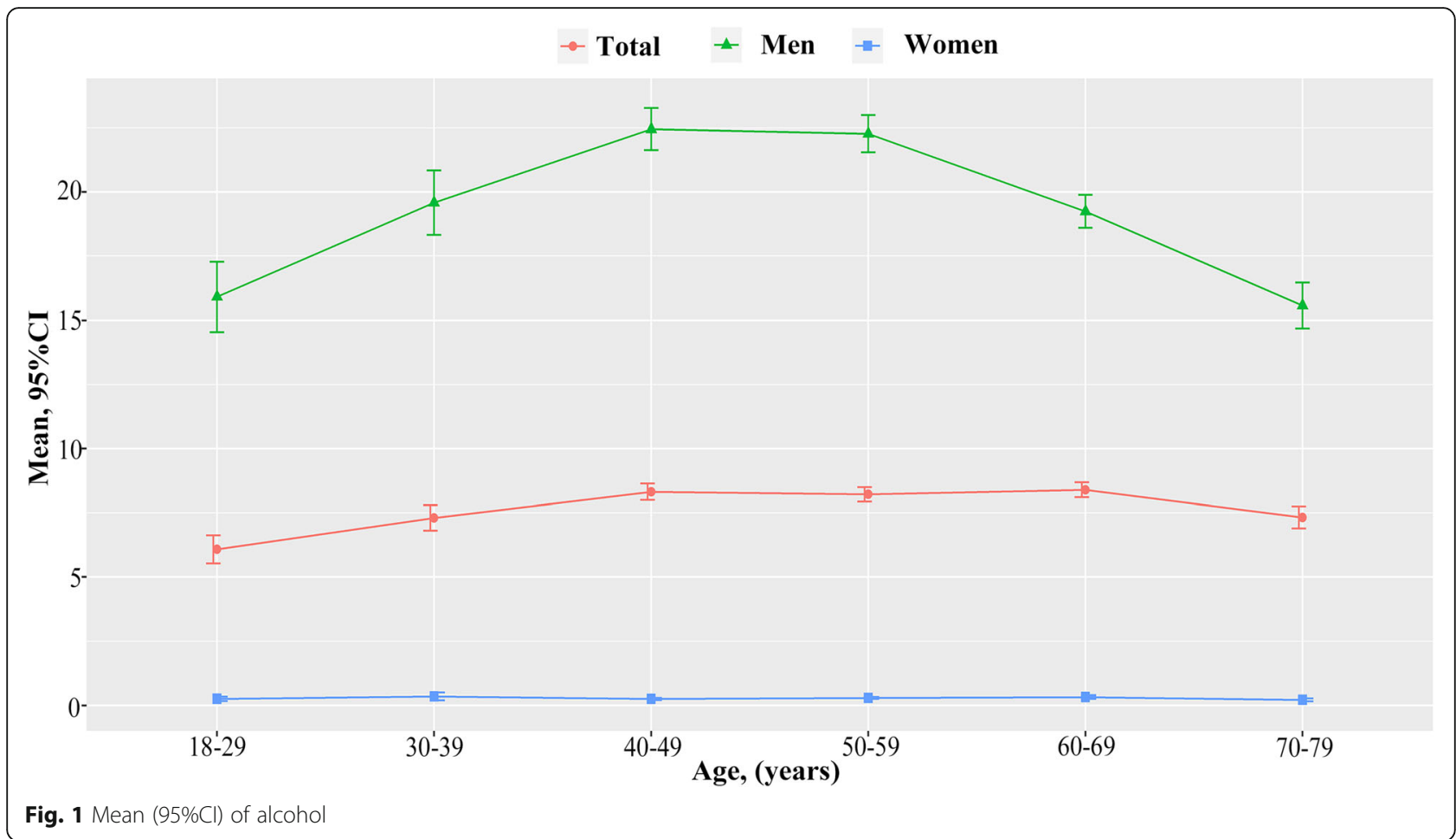

drinkers among rural women. In addition, compared to non-drinkers, the association between alcohol consumption and T2DM was observed only in low-risk drinkers for women. Multivariable restricted cubic regression splines were conducted with three knots placed at the fifth, 50th and 95th to visually explore the association between age of starting to consume alcohol, number of years of consuming alcohol and T2DM. The odds of T2DM increased with the increment of number of years of consuming alcohol (Fig. S4) and alcohol intake (Fig. S5) and with the decrement of the age of starting to consume alcohol (Fig. S6) in total population and men after adjusting potential confounders. In addition, we analyzed the relationship between drinking types and T2DM (Table S5). Of the many types of alcoholic beverages, only liquor might increase the risk of T2DM $(1.002(1.001,1.003))$ among men. No association between type of alcoholic and T2DM was found in women.

\section{Associations between number of years of abstinence from alcohol and T2DM}

Table 3 shows the association of abstinence duration with T2DM by sex. We further found that the risk of T2DM decreased as the number of years of abstinence increases and no association between alcohol abstinence and T2DM was found after more than 10 years of abstinence in men. No association between abstinence duration and T2DM was found among women.

\section{Discussion}

In the present study, the prevalence of alcohol consumption was much higher in men $(41.74 \%)$ than in women (2.59\%). There was a statistically significant U-shaped association between mean alcohol consumption level and age group in men, with the highest in the 40-49 years group. Higher rates of initiation of alcohol consumption before age 18 (26.99\% in men and $11.41 \%$ in women). Most people start alcohol consumption at the age of 18 to 29 (58.46\% in men and $33.16 \%$ in women). In addition, the vast majority of people quit drinking for health reasons such as disease ( $88.37 \%$ in men and 62.30 in women). For men, abstinence from alcohol was associated with an increased risk of T2DM, whereas current drinkers were not associated with T2DM. Further analysis of alcohol drinkers revealed that only high-risk drinkers of WHO drinking risk levels increased the risk of T2DM. The risk of T2DM increased as the age of starting to consume alcohol decreased and as the number of years of consuming alcohol and the alcohol intake increased only in men. The association between alcohol consumption and T2DM was only observed in women who were low-risk drinkers. In addition, only liquor was associated with a higher risk of T2DM in men, while no association between alcohol type and T2DM was found in women. We further found that the risk of T2DM decreased as the number of years of abstinence increases and no association between alcohol abstinence and T2DM was found after more than 10 years of abstinence among men. 
Table 2 The association of drinking status with T2DM by sex

\begin{tabular}{|c|c|c|c|c|}
\hline Drinking status & $\mathrm{N}(\%)$ & $\begin{array}{l}\text { Model } 1 \\
\text { OR }(95 \% \mathrm{Cl})\end{array}$ & $\begin{array}{l}\text { Model } 2 \\
\text { OR }(95 \% \mathrm{Cl})\end{array}$ & $\begin{array}{l}\text { Model } 3 \\
\text { OR }(95 \% \mathrm{Cl})\end{array}$ \\
\hline \multicolumn{5}{|l|}{ Total } \\
\hline Never drinker & $30,347(77.30)$ & 1 [Reference] & 1 [Reference] & 1 [Reference] \\
\hline Former drinker & $1832(4.67)$ & $1.41(1.22,1.62)^{*}$ & $1.45(1.24,1.70)^{*}$ & $1.42(1.21,1.66)^{*}$ \\
\hline Current drinker & $7080(18.03)$ & $0.78(0.71,0.86)^{*}$ & $1.04(0.92,1.16)$ & $1.03(0.91,1.15)$ \\
\hline \multicolumn{5}{|c|}{ WHO risk drinking levels } \\
\hline Low-risk drinkers & $5447(61.71)$ & $0.84(0.76,0.94)^{*}$ & $1.06(0.94,1.19)$ & $1.04(0.92,1.18)$ \\
\hline Medium-risk drinkers & $1848(20.94)$ & $0.96(0.82,1.13)$ & $1.23(1.03,1.46)^{*}$ & $1.22(1.02,1.46)^{*}$ \\
\hline High-risk drinkers & $1532(17.36)$ & $1.07(0.91,1.27)$ & $1.35(1.12,1.62)^{*}$ & $1.32(1.10,1.60)^{*}$ \\
\hline \multicolumn{5}{|l|}{ Men } \\
\hline Never drinker & $7257(46.85)$ & 1 [Reference] & 1 [Reference] & 1 [Reference] \\
\hline Former drinker & $1768(11.41)$ & $1.49(1.27,1.74)^{*}$ & $1.52(1.29,1.79)^{*}$ & $1.49(1.27,1.76)^{*}$ \\
\hline Current drinker & $6465(41.74)$ & $0.85(0.76,0.96)^{*}$ & $1.00(0.88,1.14)$ & $1.00(0.88,1.13)$ \\
\hline \multicolumn{5}{|c|}{ WHO risk drinking levels } \\
\hline Low-risk drinkers & $4909(60.13)$ & $0.92(0.81,1.05)$ & $1.06(0.93,1.21)$ & $1.06(0.92,1.21)$ \\
\hline Medium-risk drinkers & $1763(21.59)$ & $1.03(0.86,1.23)$ & $1.19(0.99,1.43)$ & $1.18(0.98,1.42)$ \\
\hline High-risk drinkers & $1492(18.28)$ & $1.13(0.94,1.36)$ & $1.32(1.09,1.60)^{*}$ & $1.29(1.06,1.57)^{*}$ \\
\hline \multicolumn{5}{|l|}{ Women } \\
\hline Never drinker & 23,090 (97.14) & 1 [Reference] & 1 [Reference] & 1 [Reference] \\
\hline Former drinker & $64(0.27)$ & $1.32(0.63,2.77)$ & $1.35(0.63,2.88)$ & $1.26(0.59,2.71)$ \\
\hline Current drinker & $615(2.59)$ & $0.51(0.35,0.72)$ & $0.60(0.42,0.86)^{*}$ & $0.57(0.40,0.82)^{*}$ \\
\hline \multicolumn{5}{|c|}{ WHO risk drinking levels } \\
\hline Low-risk drinkers & $538(81.15)$ & $0.55(0.38,0.79)^{*}$ & $0.66(0.45,0.96)^{*}$ & $0.61(0.42,0.88)^{*}$ \\
\hline Medium-risk drinkers & $85(12.82)$ & $0.70(0.31,1.61)$ & $0.67(0.29,1.56)$ & $0.75(0.32,1.75)$ \\
\hline High-risk drinkers & $40(6.03)$ & $1.03(0.35,2.88)$ & $1.04(0.36,2.98)$ & $1.05(0.37,3.02)$ \\
\hline
\end{tabular}

$O R$ odds ratios, $\mathrm{Cl}$ confidence intervals

$*, P<0.05$

WHO risk drinking levels, low-risk drinkers ( $>0$ to $25 \mathrm{~g} / \mathrm{d}$ for men, $>0$ to $15 \mathrm{~g} / \mathrm{d}$ for women), medium-risk drinkers ( $>25$ to $60 \mathrm{~g} / \mathrm{d}$ for men, $>15$ to $40 \mathrm{~g} / \mathrm{d}$ for women), high-risk drinkers ( $>60 \mathrm{~g} / \mathrm{d}$ for men, $>40 \mathrm{~g} / \mathrm{d}$ for women)

Model 1: unadjusted; Model 2: adjusted for age, gender, education level, marital status, and smoking; Model 3: adjusted for model 2 plus family histories of T2DM, more vegetables and fruits intake, high fat diet, physical activity

There are many studies that confirm higher rates of alcohol consumption in rural areas than in urban areas $[29,30]$. Liqueur consumption was more common in rural China. This might be related to the emergence of large amounts of homemade alcohol in rural China [31], which might further increase the consumption of alcohol among rural men [32]. This also suggests that more attention is given to the problem of alcohol consumption in rural areas and that active control measures are needed to intervene in alcohol consumption. Our study found a significant U-shaped association between mean levels of alcohol consumption and age group in men, with the highest mean values for participants aged 40 to 49 years. In contrast, one study showed that drinking rates increased with age, with higher rates in the older age groups [31]. This discrepancy might be the result of a declining workforce among older adults without retirement pay to the extent that they can hardly afford daily alcohol expenditures. The trend of liquor consumption with age was the opposite of beer, with more rural Chinese men preferring to consume liquor as they get older. In China, young people preferred to drink beer, and older people might use liqueurs in social gatherings to enhance the atmosphere or add emotion [30]. In addition, we found that $25.96 \%$ started drinking before the age of 18 and the lowest age of starting to drink was 3. Alcohol use is prevalent among adolescents in China [33]. This might be because rural populations are not fully aware of the dangers of alcohol consumption. More public measures should be established to address the problem of underage drinking.

Our study found that reducing the amount of alcohol consumed or adhering to abstinence from alcohol was advantageous in reducing the risk of T2DM. Previous 
Table 3 The association of abstinence duration with T2DM by sex

\begin{tabular}{|c|c|c|c|c|}
\hline \multirow{2}{*}{$\begin{array}{l}\text { Abstinence } \\
\text { duration }\end{array}$} & \multirow[t]{2}{*}{ N (\%) } & Model 1 & \multirow{2}{*}{$\begin{array}{l}\text { Model } 2 \\
\text { OR }(95 \% \mathrm{Cl})\end{array}$} & \multirow{2}{*}{$\begin{array}{l}\text { Model } 3 \\
\text { OR }(95 \% \mathrm{Cl})\end{array}$} \\
\hline & & OR $(95 \% \mathrm{Cl})$ & & \\
\hline \multicolumn{5}{|l|}{ Total } \\
\hline Never drinker & 30,347 (77.30) & 1 [Reference] & 1 [Reference] & 1 [Reference] \\
\hline$\leq 1^{a}$ & $372(0.95)$ & $1.59(1.19,2.13)^{*}$ & $1.84(1.36,2.49)^{*}$ & $1.74(1.28,2.37)^{*}$ \\
\hline $2-5^{a}$ & $550(1.40)$ & $1.50(1.18,1.92)^{*}$ & $1.66(1.29,2.15)^{*}$ & $1.66(1.28,2.16)^{*}$ \\
\hline $6-10^{a}$ & $357(0.91)$ & $1.45(1.07,0.98)$ & $1.52\left(1.10,2.09^{*}\right)$ & $1.51(1.10,2.08)^{*}$ \\
\hline $11-15^{\mathbf{a}}$ & $204(0.52)$ & $1.38(0.91,2.08)$ & $1.43(0.94,2.19)$ & $1.43(0.94,2.20)$ \\
\hline$\geq 16^{\mathbf{a}}$ & $337(0.86)$ & $1.02(0.71,1.47)$ & $0.90(0.62,1.30)$ & $0.87(0.60,1.26)$ \\
\hline \multicolumn{5}{|l|}{ Men } \\
\hline Never drinker & 7257 (46.85) & 1 [Reference] & 1 [Reference] & 1 [Reference] \\
\hline$\leq 1^{a}$ & $358(2.31)$ & $1.68(1.24,2.27)^{*}$ & $1.80(1.32,2.44)^{*}$ & $1.68(1.23,2.30)^{*}$ \\
\hline $2-5^{a}$ & $526(3.40)$ & $1.61(1.25,2.09)^{*}$ & $1.66(1.28,2.15)^{*}$ & $1.66(1.28,2.17)^{*}$ \\
\hline $6-10^{a}$ & $345(2.23)$ & $1.48(1.07,2.04)^{*}$ & $1.48(1.07,2.06)^{*}$ & $1.49(1.07,2.08)^{*}$ \\
\hline $11-15^{\mathbf{a}}$ & $199(1.28)$ & $1.49(0.98,2.27)$ & $1.50(0.98,2.28)$ & $1.52(0.99,2.33)$ \\
\hline$\geq 16^{\mathbf{a}}$ & $330(2.13)$ & $1.07(0.73,1.55)$ & $0.99(0.68,1.45)$ & $0.96(0.66,1.41)$ \\
\hline \multicolumn{5}{|l|}{ Women } \\
\hline Never drinker & 23,090 (97.14) & 1 [Reference] & 1 [Reference] & 1 [Reference] \\
\hline$\leq 1^{a}$ & $14(0.06)$ & $1.54(0.34,6.87)$ & $1.53(0.33,7.21)$ & $1.43(0.30,6.76)$ \\
\hline $2-5^{a}$ & $24(0.10)$ & $0.84(0.20,3.57)$ & $1.12(0.26,4.90)$ & $1.07(0.24,4.69)$ \\
\hline $6-10^{a}$ & $12(0.05)$ & $3.07(0.83,11.35)$ & $2.68(0.71,10.07)$ & $2.30(0.60,8.78)$ \\
\hline $11-15^{a}$ & $5(0.02)$ & $N A$ & $N A$ & $N A$ \\
\hline$\geq 16^{\mathrm{a}}$ & $7(0.03)$ & $1.54(0.19,12.76)$ & $1.02(0.12,8.62)$ & $0.99(0.12,8.31)$ \\
\hline
\end{tabular}

$O R$ odds ratios, $\mathrm{Cl}$ confidence intervals

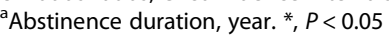

Model: unadjusted; Model 2: adjusted for age, gender, education level, marital status, and smoking; Model 3: adjusted for model 2 plus family histories of T2DM, more vegetables and fruits intake, high fat diet, physical activity

studies have found that moderate alcohol use was associated with a lower incidence of diabetes [12, 34-36]. There was evidence that moderate consumption of alcohol increases insulin sensitivity [37, 38]. Moderate alcohol consumption once a day significantly reduces fasting blood glucose levels [39]. Increasing alcohol consumption was significantly associated with lower glycated hemoglobin concentrations [40]. A study has indicated that light and moderate alcohol consumption weakens the link between obesity and glycemic status [41], which of one possible explanation is that alcohol suppresses obesity-induced insulin resistance. An experimental study in mice fed a high-fat diet showed that alcohol increased insulin sensitivity by upregulating anti-insulin sensitivity genes and that obesity-related alterations in insulin sensitivity were combined with alterations in insulin sensitivity genes [42]. Moderate alcohol consumption may inhibit obesity-induced insulin resistance by increasing lipocalin, growth hormone-releasing peptide, and anti-inflammatory molecules [42, 43]. Nevertheless, several other studies have suggested that moderate alcohol consumption was not associated with a reduced risk of developing T2DM $[44,45]$. The mechanisms underlying the beneficial effects of moderate alcohol consumption on diabetes still require further in-depth study. With ongoing research, a recent meta-analysis revealed that the reduced risk for moderate drinkers may be limited to women and non-Asian populations [15], which was similar to our findings that low-risk drinking levels might reduce the risk of T2DM only in women, and our results added to the evidence of rural populations in China. In addition, we conducted the first study on the relationship between alcohol consumption and T2DM in rural Chinese. And we found that high-risk drinking levels might increase the risk of T2DM, however, we did not find any association between low-risk drinking level or medium-risk drinking level and T2DM. The study of the JPHC study cohort I found similar results that moderate to high alcohol consumption was positively associated with the incidence of diabetes in Japanese [46]. Our study further supports that reducing alcohol consumption $[19,20]$ are beneficial in reducing the risk of T2DM in high-risk drinkers, although no association was found between low-risk drinking level or 
medium-risk drinking level and T2DM. Our research supports the beneficial effects of abstinence and adherence to abstinence might counteract the harmful effects of alcohol consumption. Our further study found that alcohol abstinence increased the risk of T2DM, while current drinkers were not associated with T2DM. This was consistent with the findings of a study of African American women [47]. Moreover, the risk of T2DM decreased as the number of years of abstinence increases and no association between alcohol abstinence and T2DM was found after more than 10 years of abstinence. The reason for this result might be that our research showed that the vast majority of reasons for abstaining from drinking were due to health reasons such as illness [48]. And current drinkers might be in relatively good health. In addition to this we also found that the risk of T2DM increased as the age of starting to consume alcohol decreased and as the number of years of consuming alcohol and the alcohol intake increased only in men. Our results further demonstrated the harmful effects of alcohol. The later you start drinking, the shorter you drink, and the smaller the amount of alcohol you drink, the more beneficial it is to your health.

The limitations of our study should be considered. First, our findings were from a cross-sectional study and therefore do not accurately describe causality. Secondly, the use of self-report questionnaires might lead to recall bias in the collection of data. Thirdly, some participants might have given subjectively evasive answers to questions about alcohol consumption. Alcohol consumption might be underestimated. In addition, the sample size of women drinking participants was relatively small. The impact of alcohol consumption on the health of the women population needs to be further explored.

\section{Conclusion}

The risk of T2DM increased as the age of starting to consume alcohol decreased and as the number of years of consuming alcohol and the alcohol intake increased only in men. After grouping abstainers by the duration of abstinence and grouping drinkers by the amount of alcohol they consumed, we further found that the risk of T2DM decreased as the number of years of abstinence increases and no association between alcohol abstinence and T2DM was found after more than 10 years of abstinence among men. Our findings indicated that reducing the amount of alcohol consumed and adhering to abstinence from alcohol consumption is beneficial in reducing the risk of T2DM.

\section{Abbreviations}

T2DM: Type 2 diabetes mellitus; WHO: World Health Organization; MI: Body mass index; FBG: Fasting blood glucose

\section{Supplementary Information}

The online version contains supplementary material available at https://doi. org/10.1186/s12889-021-11681-0.

\section{Additional file 1.}

\section{Acknowledgements}

The authors thank all of the participants, coordinators, and administrators for their support during the research. In addition, the authors would like to thank Tanko Abdulai for his critical reading of the manuscript.

\section{Authors' contributions}

Xueyan Wu: Investigation, Data curation, Methodology, Formal analysis, Visualization, Writing-Original Draft. Xiaotian Liu: Investigation, Data curation, Writing-Review \& Editing. Wei Liao: Investigation, Validation, Writing-Review \& Editing. Ning Kang: Investigation, Writing-Review \& Editing. Xiaokang Dong: Investigation, Writing-Review \& Editing. Tanko Abdulai: Investigation, Data curation, Writing-Review \& Editing. Zhihan Zhai: Investigation, Data curation, Writing-Review \& Editing. Chongjian Wang: Conceptualization, Methodology, Investigation, Validation, Supervision, Funding acquisition, Project administration, Writing-Original Draft. Xiaoqiong Wang: Investigation, Validation, Writing-Review \& Editing. Yuqian Li: Investigation, Writing-Review \& Editing. The author(s) read and approved the final manuscript.

\section{Funding}

This research was supported by the Foundation of National Key Program of Research and Development of China (Grant NO: 2016YFC0900803), National Natural Science Foundation of China (Grant NO: 81930092, 81573243, 81602925), Science and Technology Innovation Team Support Plan of Colleges and Universities in Henan Province (Grant NO:21IRTSTHNO29), Discipline Key Research and Development Program of Zhengzhou University (Grant NO: XKZDQY202008, XKZDQY202002). The funders had no role in the study design, data collection and analysis, decision to publish, or preparation of the manuscript.

\section{Availability of data and materials}

The datasets used and/or analyzed during the current study available from the corresponding author on reasonable request.

\section{Declarations}

\section{Ethics approval and consent to participate}

Ethics approval was obtained from the "Zhengzhou University Life Science Ethics Committee", and written informed consent was obtained for all participants. Ethic approval code: [2015] MEC (S128). Written informed consent was obtained from all participants.

\section{Consent for publication}

Not applicable.

\section{Competing interests}

All authors have read and approved this version of the article, and declared that they had no competing or financial interests to disclosure.

\section{Author details}

'Department of Epidemiology and Biostatistics, College of Public Health, Zhengzhou University, 100 Kexue Avenue, Zhengzhou 450001, Henan, P. R. China. ${ }^{2}$ Department of Preventive Medicine, Henan University of Chinese Medicine, Zhengzhou, Henan, P. R. China. ${ }^{3}$ Department of Economics, School of Business, Zhengzhou University, Zhengzhou, Henan, P. R. China.

${ }^{4}$ Department of Clinical Pharmacology, School of Pharmaceutical Science, Zhengzhou University, Zhengzhou, Henan, P. R. China.

Received: 5 March 2021 Accepted: 29 August 2021

Published online: 09 September 2021

\section{References}

1. Rehm J, Room R, Monteiro M, Gmel G, Graham K, Rehn N, et al. Alcohol as a risk factor for global burden of disease. Eur Addict Res. 2003;9(4):157-64. https://doi.org/10.1159/000072222. 
2. Forouzanfar MH, Alexander L, Anderson HR, Bachman VF, Biryukov S, Brauer $\mathrm{M}$, et al. Global, regional, and national comparative risk assessment of 79 behavioural, environmental and occupational, and metabolic risks or clusters of risks in 188 countries, 1990-2013: a systematic analysis for the Global Burden of Disease Study 2013. Lancet (London, England). 2015; 386(10010):2287-323. https://doi.org/10.1016/S0140-6736(15)00128-2.

3. World Health Organisation: Global status report on alcohol and health, 2014: WHO; 2014.

4. Alcohol. Available online: http://www.who.int/news-room/fact-sheets/deta il/alcohol. Accessed 24 Oct 2018.

5. Xu X, Zhao L, Fang H, Guo Q, Wang X, Yu W, et al. Status of alcohol drinking among population aged 15 and above in China in 2010-2012. J Hygiene Res. 2016;45(4):534-67 PubMed PMID: 29903318.

6. Lee Y-H, Wang Z, Chiang TC, Liu C-T. Beverage Intake, Smoking Behavior, and Alcohol Consumption in Contemporary China-A Cross-Sectional Analysis from the 2011 China health and nutrition survey. Int J Environ Res Public Health. 2017;14(5, 5). https://doi.org/10.3390/ijerph14050493.

7. Chan JCN, Zhang Y, Ning G. Diabetes in China: a societal solution for a personal challenge. Lancet Diabetes Endocrinol. 2014;2(12):969-79. https:// doi.org/10.1016/S2213-8587(14)70144-5.

8. Xu Y, Wang L, He J, Bi Y, Li M, Wang T, et al. Prevalence and control of diabetes in Chinese adults. JAMA. 2013;310(9):948-59. https://doi.org/10.1 001/jama.2013.168118.

9. Ajani UA, Hennekens $\mathrm{CH}$, Spelsberg A, Manson JE. Alcohol consumption and risk of type 2 diabetes mellitus among US male physicians. Arch Intern Med. 2000;160(7):1025-30. https://doi.org/10.1001/archinte.160.7.1025.

10. Wei M, Gibbons LW, Mitchell TL, Kampert JB, Blair SN. Alcohol intake and incidence of type 2 diabetes in men. Diabetes Care. 2000;23(1):18-22. https://doi.org/10.2337/diacare.23.1.18.

11. Koppes LLJ, Dekker JM, Hendriks HFJ, Bouter LM, Heine RJ. Moderate alcohol consumption lowers the risk of type 2 diabetes: a meta-analysis of prospective observational studies. Diabetes Care. 2005;28(3):719-25. https:// doi.org/10.2337/diacare.28.3.719.

12. Howard AA, Arnsten JH, Gourevitch MN. Effect of alcohol consumption on diabetes mellitus: a systematic review. Ann Intern Med. 2004;140(3):211-9. https://doi.org/10.7326/0003-4819-140-6-200403160-00011.

13. Li X-H, Yu F-F, Zhou Y-H, He J. Association between alcohol consumption and the risk of incident type 2 diabetes: a systematic review and doseresponse meta-analysis. Am J Clin Nutr. 2016;103(3):818-29. https://doi.org/1 0.3945/ajcn.115.114389.

14. Hodge AM, English DR, O'Dea K, Giles GG. Alcohol intake, consumption pattern and beverage type, and the risk of type 2 diabetes. Diabet Med. 2006;23(6):690-7. https://doi.org/10.1111/j.1464-5491.2006.01864.x.

15. Knott C, Bell S, Britton A. Alcohol consumption and the risk of type 2 diabetes: a systematic review and dose-response Meta-analysis of more than 1.9 million individuals from 38 observational studies. Diabetes Care. 2015;38(9):1804-12. https://doi.org/10.2337/dc15-0710.

16. Sakai Y, Yamaji T, Tabata S, Ogawa S, Yamaguchi $K$, Mineshita M, et al. Relation of alcohol use and smoking to glucose tolerance status in Japanese men. Diabetes Res Clin Pract. 2006;73(1):83-8. https://doi.org/10.1 016/j.diabres.2005.12.010

17. Sawada SS, Lee IM, Muto T, Matuszaki K, Blair SN. Cardiorespiratory fitness and the incidence of type 2 diabetes: prospective study of Japanese men. Diabetes Care. 2003;26(10):2918-22. https://doi.org/10.2337/diacare.26.10.291 8.

18. Alcohol use and burden for 195 countries and territories, 1990-2016: a systematic analysis for the Global Burden of Disease Study 2016. Lancet (London, England). 2018;392(10152):1015-35. doi: https://doi.org/10.1016/ S0140-6736(18)31310-2

19. Witkiewitz K, Pearson MR, Hallgren KA, Maisto SA, Roos CR, Kirouac M, et al. Who achieves low risk drinking during alcohol treatment? An analysis of patients in three alcohol clinical trials. Addiction. 2017;112(12):2112-21. https://doi.org/10.1111/add.13870.

20. Hasin DS, Wall M, Witkiewitz K, Kranzler HR, Falk D, Litten $\mathrm{R}$, et al. Change in non-abstinent WHO drinking risk levels and alcohol dependence: a 3 year follow-up study in the US general population. Lancet Psychiatry. 2017:4(6): 469-76. https://doi.org/10.1016/S2215-0366(17)30130-X.

21. Knox J, Scodes J, Witkiewitz K, Kranzler HR, Mann K, O'Malley SS, et al. Reduction in World Health Organization risk drinking levels and cardiovascular disease. Alcohol Clin Exp Res. 2020:44(8):1625-35. https://doi. org/10.1111/acer.14386.
22. Liu X, Mao Z, Li Y, Wu W, Zhang X, Huo W, et al. The Henan rural cohort: a prospective study of chronic non-communicable diseases. Int J Epidemiol. 2019;48(6):1756-1756j. https://doi.org/10.1093/ije/dyz039.

23. Wang Y, Li Y, Liu X, Tu R, Zhang H, Qian X, et al. The prevalence and related factors of familial hypercholesterolemia in rural population of China using Chinese modified Dutch lipid clinic network definition. BMC Public Health. 2019;19(1):837. https://doi.org/10.1186/s12889-019-7212-4.

24. Bauman A, Bull F, Chey T, Craig CL, Ainsworth BE, Sallis JF, et al. The International Prevalence Study on Physical Activity: results from 20 countries. Int J Behav Nutr Phys Act. 2009;6:21. https://doi.org/10.1186/14795868-6-21.

25. Xue Y, Yang K, Wang B, Liu C, Mao Z, Yu S, et al. Reproducibility and validity of an FFQ in the Henan rural cohort study. Public Health Nutr. 2019;23(1):17. https://doi.org/10.1017/s1368980019002416.

26. Diagnosis and classification of diabetes mellitus. Diabetes Care. 2014;37 Suppl 1:S81-S90. https://doi.org/10.2337/dc14-S081.

27. Chinese Nutrition Society. Chinese Dietary Guidelines summary. Beijing: People's Medical Publishing House; 2016.

28. World health organization. International guide for monitoring alcohol consumption and related harm. 2000 ed. Geneva: WHO; 2000. p. 51.

29. Yu H, Wang T, Zhang R, Yan J, Jiang F, Li S, et al. Alcohol consumption and its interaction with genetic variants are strongly associated with the risk of type 2 diabetes: a prospective cohort study. Nutr Metab (Lond). 2019;16:64. https://doi.org/10.1186/s12986-019-0396-X.

30. Liu R, Chen L, Zhang F, Zhu R, Lin X, Meng X, et al. Trends in Alcohol Intake and the Association between Socio-Demographic Factors and Volume of Alcohol Intake amongst Adult Male Drinkers in China. Int J Environ Res Public Health. 2019;16(4). https://doi.org/10.3390/ijerph16040573.

31. Zhou L, Conner KR, Caine ED, Xiao S, Xu L, Gong Y, et al. Epidemiology of alcohol use in rural men in two provinces of China. J Stud Alcohol Drugs. 2011;72(2):333-40. https://doi.org/10.15288/jsad.2011.72.333.

32. Yang $L$, Zhou M, Sherliker $P$, Cai $Y$, Peto $R$, Wang $L$, et al. Alcohol drinking and overall and cause-specific mortality in China: nationally representative prospective study of 220,000 men with 15 years of follow-up. Int J Epidemiol. 2012;41(4):1101-13. https://doi.org/10.1093/ije/dys075.

33. Xing Y, Ji C, Zhang L. Relationship of binge drinking and other healthcompromising behaviors among urban adolescents in China. J Adolesc Health. 2006;39(4):495-500. https://doi.org/10.1016/j.jadohealth.2006.03.014.

34. Schrieks IC, Heil ALJ, Hendriks HFJ, Mukamal KJ, Beulens JWJ. The effect of alcohol consumption on insulin sensitivity and glycemic status: a systematic review and meta-analysis of intervention studies. Diabetes Care. 2015;38(4): 723-32. https://doi.org/10.2337/dc14-1556.

35. Zhang S, Liu Y, Wang G, Xiao X, Gang X, Li F, et al. The relationship between alcohol consumption and incidence of Glycometabolic abnormality in middle-aged and elderly Chinese men. Int J Endocrinol. 2016;2016:1983702-7. https://doi.org/10.1155/2016/1983702.

36. Baliunas DO, Taylor BJ, Irving H, Roerecke M, Patra J, Mohapatra S, et al. Alcohol as a risk factor for type 2 diabetes: a systematic review and metaanalysis. Diabetes Care. 2009;32(11):2123-32. https://doi.org/10.2337/dc090227.

37. Davies MJ, Baer DJ, Judd JT, Brown ED, Campbell WS, Taylor PR. Effects of moderate alcohol intake on fasting insulin and glucose concentrations and insulin sensitivity in postmenopausal women: a randomized controlled trial. JAMA. 2002;287(19):2559-62. https://doi.org/10.1001/jama.287.19.2559.

38. Facchini F, Chen YD, Reaven GM. Light-to-moderate alcohol intake is associated with enhanced insulin sensitivity. Diabetes Care. 1994;17(2):1159. https://doi.org/10.2337/diacare.17.2.115

39. Shai I, Wainstein J, Harman-Boehm I, Raz I, Fraser D, Rudich A, et al. Glycemic effects of moderate alcohol intake among patients with type 2 diabetes: a multicenter, randomized, clinical intervention trial. Diabetes Care. 2007;30(12):3011-6. https://doi.org/10.2337/dc07-1103.

40. Ahmed AT, Karter AJ, Warton EM, Doan JU, Weisner CM. The relationship between alcohol consumption and glycemic control among patients with diabetes: the Kaiser Permanente northern California diabetes registry. J Gen Intern Med. 2008;23(3):275-82. https://doi.org/10.1007/s11606-007-0502-z.

41. Wakabayashi I. Light-to-moderate alcohol drinking reduces the impact of obesity on the risk of diabetes mellitus. J Stud Alcohol Drugs. 2014;75(6): 1032-8. https://doi.org/10.15288/jsad.2014.75.1032.

42. Paulson QX, Hong J, Holcomb VB, Nunez NP. Effects of body weight and alcohol consumption on insulin sensitivity. Nutr J. 2010;9:14. Published 2010 Mar 22. https://doi.org/10.1186/1475-2891-9-14. 
43. Beulens JW, de Zoete EC, Kok FJ, Schaafsma G, Hendriks HF. Effect of moderate alcohol consumption on adipokines and insulin sensitivity in lean and overweight men: a diet intervention study. Eur J Clin Nutr. 2008;62(9): 1098-105. https://doi.org/10.1038/sj.ejcn.1602821.

44. Zilkens RR, Puddey IB. Alcohol and cardiovascular disease--more than one paradox to consider. Alcohol and type 2 diabetes--another paradox? J Cardiovasc Risk. 2003;10(1):25-30. https://doi.org/10.1097/01.hjr.0000051 965.16636.3c.

45. Saremi A, Hanson RL, Tulloch-Reid M, Williams DE, Knowler WC. Alcohol consumption predicts hypertension but not diabetes. J Stud Alcohol. 2004; 65(2):184-90. https://doi.org/10.15288/jsa.2004.65.184.

46. Waki K, Noda M, Sasaki S, Matsumura Y, Takahashi Y, Isogawa A, et al. Alcohol consumption and other risk factors for self-reported diabetes among middle-aged Japanese: a population-based prospective study in the JPHC study cohort I. Diabet Med. 2005;22(3):323-31. https://doi.org/10.1111/ j.1464-5491.2004.01403.x.

47. Boggs DA, Rosenberg L, Ruiz-Narvaez EA, Palmer JR. Coffee, tea, and alcohol intake in relation to risk of type 2 diabetes in African American women. Am J Clin Nutr. 2010;92(4):960-6. https://doi.org/10.3945/ajcn.2010.29598.

48. Fillmore KM, Kerr WC, Bostrom A. Changes in drinking status, serious illness and mortality. J Stud Alcohol. 2003;64(2):278-85. https://doi.org/10.15288/ jsa.2003.64.278.

\section{Publisher's Note}

Springer Nature remains neutral with regard to jurisdictional claims in published maps and institutional affiliations.

Ready to submit your research? Choose BMC and benefit from:

- fast, convenient online submission

- thorough peer review by experienced researchers in your field

- rapid publication on acceptance

- support for research data, including large and complex data types

- gold Open Access which fosters wider collaboration and increased citations

- maximum visibility for your research: over $100 \mathrm{M}$ website views per year

At $\mathrm{BMC}$, research is always in progress.

Learn more biomedcentral.com/submissions 